mittees and in other organisations, and to many spells of service as chairman he invariably brought a balanced judgement, a diplomatic touch and a quiet sense of humour. While DirectorGeneral of the Meteorological Office he took a prominent part in the activities of the World Meteorological Organisation, especially as a member of its Executive Committee. $\mathrm{He}$ was President of the Royal Meteorological Society 1953-55. He also found time for the duties of a Justice of the Peace and for those of a member of the Council of the University College of Wales, Aberystwyth, of which he was Vice-President in his last few years.

F. Pasquill

\section{A. D. Walsh}

Professor A. Donald Walsh FRS died in Dundee, after a long illness, on 23 April 1977 in his sixty-first year. $\mathrm{He}$ was educated at Loughborough Grammar School and Corpus Christi College, Cambridge, where he was a Mawson Scholar. In 1938 he started research in vacuum ultra-violet spectroscopy under the direction of Professor W. C. Price and continued as an ICI Research Fellow until 1949, when he accepted a lectureship at Leeds University. In 1953 he was promoted to a Readership, and two years later was invited to take the Baxter Chair of Chemistry at Queen's College, Dundee, which was then part of the University of St. Andrews. In 1967, when Queen's College became the University of Dundee, Professor Walsh was appointed Dean of the Science Faculty. He was elected to the Royal Society of Edinburgh in 1959 and to the Royal Society in 1964.

Donald Walsh will always be remembered for his enthusiasm. Whether he was lecturing to a first-year class, discussing his latest research, or watching the flight of a bird while driving erratically along a country road, he radiated a fascinating and infectious enthusiasm for his subject.

It was this enthusiasm which marked his rise to the heights of his profession. The investigation of the electronic structure of small molecules and the nature of valence and chemical bonding were, for him, an absorbing study throughout his career. The topic suited his enquiring mind ideally, for he loved to put his ideas to the test and spent very many happy days fitting together his theories and his experimental spectra.

During the war, when it became necessary for research to have more practical application, Donald Walsh became involved in problems of gaseous combustion, such as the suppression of the exhaust flames which revealed the presence of our aeroplanes in the sky at night. After the war, he became more interested in the mechanism of gaseous combustion reactions, and in particular with the mechanism of anti-knocks in petrol engines. In this he was associated with Riccardo Ltd and later with Octel Ltd who still employ a number of his former students. Those privileged to hear him present his research papers in the 1950 s and 1960s will clearly recall the rival theories on anti-knock action put forward by Professors R. G. W. Norrish and A. D. Walsh, the debates being enlivened by the completely different personalities of these two eminent scientists. Donald Walsh was fond of simple experiments to demonstrate his ideas. One remembers the hydrogen peroxide which usually hit the ceiling in a demonstration that peroxides are rapidly decomposed by particulate lead oxide (an important part of his theory of the anti-knock action of lead alkyls.)

In Dundee his gentlemanly charm and hospitality quickly gained for him the loyalty of a department which rapidly grew under his direction and enthusiasm. His research students enjoyed many happy Saturday afternoons helping him construct his large garden, and they appreciated the generous quantities of Elin Walsh's magnificent teas which contrasted so markedly with student fare.

When Dundee gained independent status as a university in 1967, Donald Walsh was the obvious choice for Dean of the Faculty of Science-a Faculty which might have disappeared earlier but for his efforts. Extra duties did not deter him, and he habitually arrived in the Department at 6 a.m. after an overnight journey from Londonhe was still there at 7 p.m.

$\mathrm{He}$ bore his long fight with Parkinson's disease with typical fortitude as he was gradually forced to retire from chemistry and from the department to which he had devoted so much of his time and energy.

$$
\begin{aligned}
& \text { D. E. Hoare } \\
& \text { P. A. Warsop }
\end{aligned}
$$

\section{R. D. Brauer}

Richard Dagobert Brauer, who was one of the leading pure mathematicians of this century, died on 17 April 1977 at Belmont, Massachusetts. Born in Berlin in 1901, he studied at the university there under the distinguished algebraist Issai Schur. He taught at Königsberg until the political oppression in Germany forced him to leave in 1933. He held temporary posts at the University of Kentucky and the Institute for Advanced Study in Princeton. In 1935 he went to the University of Toronto, where he stayed until
1948; he then returned to the United States, and held chairs at the Universities of Michigan (1948-1952) and Harvard (1952-1971).

Brauer's work on the representation theory of groups has been a major influence in the development of algebra during the past half-century. Some of his earlier papers were concerned with the representations of semisimple continuous groups--Hermann Weyl's fundamental work on this subject appeared at about the time (1925-1926) when Brauer was presenting his doctoral thesis. Brauer's methods were more algebraic, and in some ways simpler than Weyl's. In fact Brauer worked as assistant to Weyl in Princeton in the year 1934-1935, and they wrote there a joint paper on spinors, which is the classical exposition of the mathematical background to Dirac's theory of the spinning electron.

From 1935 onwards, Brauer was increasingly concerned with the representation theory of finite groups. He developed a beautiful and deep theory of modular characters, which gave a completely new insight into the study of group characters. Group characters had been introduced in 1896 by Frobenius, and had already given, in the first decade of this century, some remarkable results on the structure of finite groups. It was Brauer who, thirty years later, resumed this work, and by the end of the 1950 s had laid the foundation of a method for attacking the very difficult problem of the classification of finite simple groups. His pioneering work was one of the starting points of a great advance in this problem. Brauer's active involvement in this research continued right up to the end of his life.

During his long career Richard Brauer received many academic honours and held some of the highest positions in his profession. But he retained a very gentle and unassuming manner, and a concern for the problems and interests of other mathematicians. His modesty about his own great achievements was proverbial-a mathematical conversation with him would usually become a conversation about the other person's work. A first impression of unworldliness was deceptive; he used his time very efficiently, and achieved a great deal in an unhurried manner. He became a kind of elder statesman among American algebraists, and his advice was sought and valued for its wisdom and humanity.

$\mathrm{He}$ is survived by his wife Ilse (née Karger) whom he married in 1925; also by his brother Alfred, and his two sons George and Fred, who are all mathematicians.

J. A. Green 